\title{
Reliability, availability, and maintainability considerations for fiber optical sensor applications
}

\author{
Rolf Brönnimann, Marcel Held, Philipp M. Nellen \\ EMPA, Swiss Federal Laboratories for Materials Testing and Research \\ CH-8600 Dübendorf, Switzerland \\ Phone: +41 182355 11, Fax:+41 182348 82, Email: rolf.broennimann@empa.ch
}

Keywords: Optical Fiber Bragg Grating Sensor, Reliability, Availability, Maintainability, Monitoring

\begin{abstract}
The paper gives an overview of reliability, availability, and maintainability of fiber optical sensors, three key factors on which standards and validation should be based and which are required for successful industrialization. The examples given are based on two long term applications with fiber optical Bragg gratings - the surveillance of two bridges (civil engineering). However, similar reflections are required for any type of application and any optical fiber sensors. Recommendations are given to improve the confidence and acceptance of possible users in fiber optical sensing systems. It is shown that with proper installation lifetimes of 50 years are possible.
\end{abstract}

\section{INTRODUCTION}

Fiber optic sensors are potentially very well suited for condition monitoring of environment, materials, structures, and facilities $[1,2]$. Measurable variables are mainly temperature, electrical current, strain and pressure. Optical fibers and sensors are often promoted to work in electromagnetic fields, at high temperature and humidity, or in aggressive chemical environment. Especially fiber Bragg grating (FBG) sensors have been demonstrated to operate in applications from airplanes to civil infrastructure like dams and bridges [3-10]. However, there is a long way from a laboratory prototype to a reliable, standardized industrial sensor system. And there is an urgent need for a common understanding of terms [11].

As sensors have to be coupled to the monitored object, they are exposed to the environment in one or the other way. Either they have to be replaceable where the consistency of data has to be considered. Or, especially if replacement is not possible, they should outlast lifetime of the monitored objects, an optimized packaging and adequate protection is particularly important. Extensive aging and reliability tests are required to determine lifetime models and parameters for fibers, coatings, and sensors. Major factors influencing lifetime of fiber optic sensors are mechanical load from strain, bending or vibration, temperature, humidity, ice and water, chemicals, as well as dust and dirt. Reliability has to be considered during sensor system design, installation, and operating phase. Correctly built in redundancies increase data integrity and reliability considerably.

In this paper, based on the examples of fiber Bragg grating systems used for long term monitoring of strain and temperature, general sensor system reliability will be discussed. In addition, specific reliability considerations and lifetime tests, especially for relevant system components like optical fibers and Bragg gratings, coatings, and adhesives will be presented. The advantages of RAM (reliability, availability, and maintainability) considerations for redundant sensor structures and sensor systems are discussed. RAM is the first steps towards standardized industrial sensor systems.

The criticality of the measured data is important and has to defined: before commissioning a monitoring system, the consequences of the data have to be assessed and failure of the monitoring system has to be considered in the case of true negatives and false positives with respect to safety, cost and liability. Questions to be asked are: are limits defined for discrimination of safe, questionable, and unsafe operation of the monitored object? However, increasing reliability and availability is also a cost factor. An essential question is if there are components whose performance cannot be verified and replaced during operation without loosing data consistency.

The paper is structured as follows: The next section shows some example of application of FGB in long term monitoring systems. Section 3 deals with the availability of sensing systems in a top down approach. Section 4 treats the 
dependability of fiber optical measurements. Reliability aspects of components are discussed in section 5. Then maintainability is shortly discussed followed by concluding remarks.

\section{EXAMPLES OF LONG TERM APPLICATIONS}

Several installations of medium and long term surveillance of structures have been installed by Empa. During heightening of a power dam specially designed sensors with embedded FGB sensors have been installed to monitor the curing of the concrete [12]. GFRP (glass fiber reinforced plastic) rock bolt have been equipped with FBG, which have been used in a tunnel to monitor the strain build up in the rock [13]. Two applications for the surveillance of two bridges are presented here in some details since they are well suited to discuss reliability aspects.

\subsection{Bridge over the Kleine Emme, Luzern}

A pedestrian bridge over the Kleine Emme is equipped with two CFRP (carbon fiber reinforced polymer) cables which both consist of 91 CFRP wires. The advantages of CFRP compared to steel are excellent corrosion resistance, high specific strength, and outstanding fatigue behavior. To verify the performance of such new designs it is necessary to monitor behavior during construction and operation. The cables are installed in steel tube below the bridge deck (Fig. 1 a)). The average strain is in the order of $8000 \mu \mathrm{m} / \mathrm{m}$. Proper strain reduction along the anchor head is critical to prevent debonding. Each cable has four active CFRP wires and a dummy wire with several embedded FBG as shown in Fig. $1 \mathrm{c}$ ) and d). They have been directly embedded during the pultrusion process in the middle of the CFRP wires. This procedure allows placing FBG not only in the free span of the wire but also in the anchor head with the critical strain decay [14]. The FBG named $A_{i}, B, C$ are inside the anchor head, $F_{i j}$ are in the free span and $T_{i j}$ are for temperature measurement and compensation. In Fig. 1b) the measurement of four FBG in the free span of one cable are given for a period of seven years. The measured values spread with time inside a band of about $100 \mu \mathrm{m} / \mathrm{m}$. The temporal variation is mainly due to temperature changes. Sensor failures and thus data loss was observed with time - the reasons are discussed below.

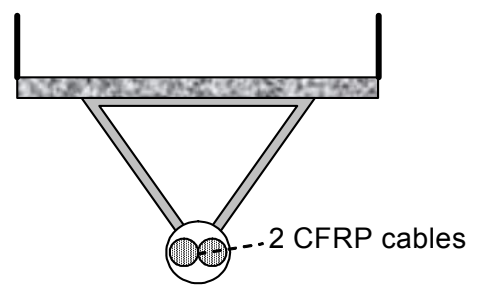

a)

- CFRP wires

O CFRP wires with FBGs

Dummy wire with FBGs 5
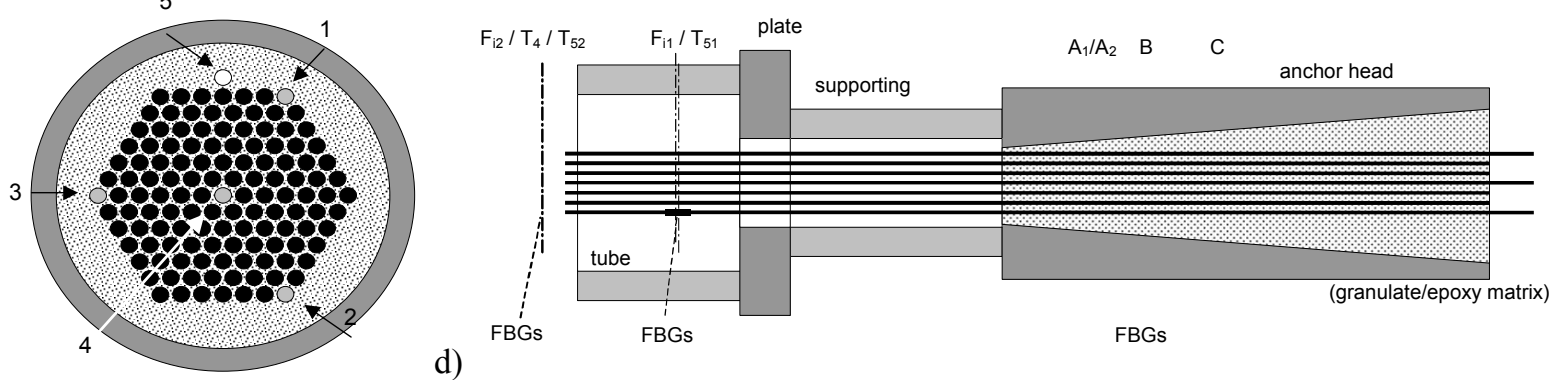

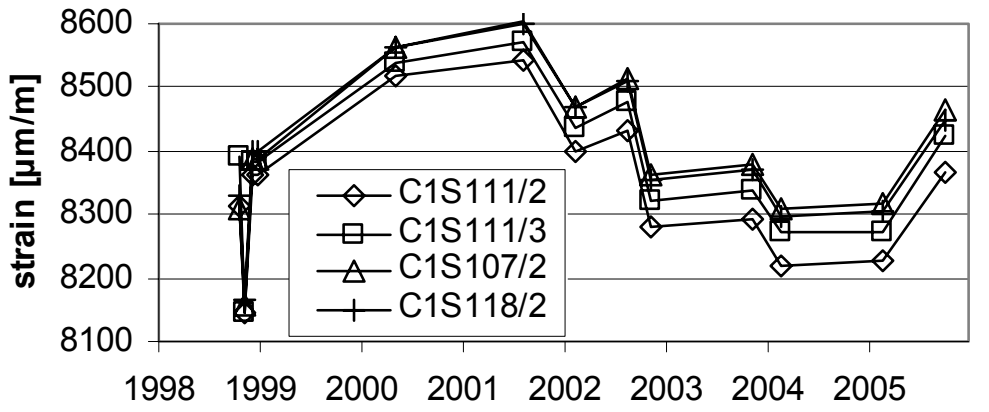

b)

$\begin{array}{llllllll}1998 & 1999 & 2000 & 2001 & 2002 & 2003 & 2004 & 2005\end{array}$ d)

c)

Fig. 1: Bridge over the Kleine Emme, cross section a), strain development on one cable b), cross sections of one cable showing the location of the FBG c) and d).

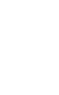




\subsection{Storchenbrücke in Winterthur}

In Winterthur, Switzerland, a stay cable bridge of length $120 \mathrm{~m}$, the Storchenbrücke, with a new suspension scheme was built in 1996 (Fig. 2). It was for the first time that on a major bridge two cables were made of 241 CFRP wires of diameter $5 \mathrm{~mm}$. The FBG based sensor system is operational since April 1996 [15].

a)

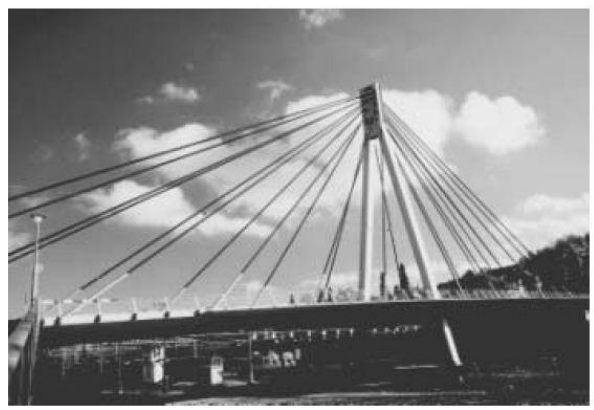

c)

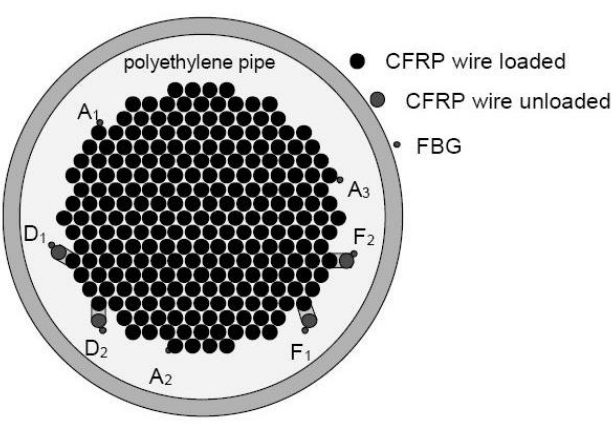

b)

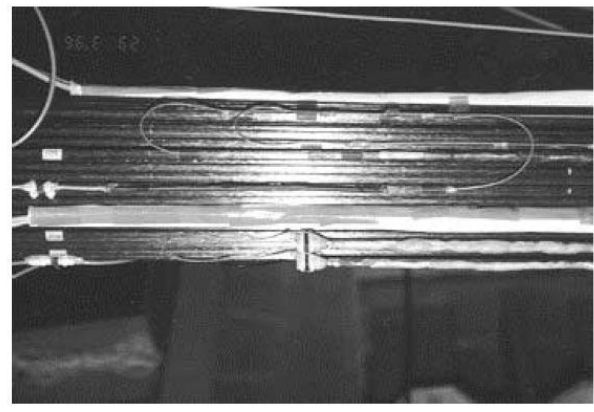

d)

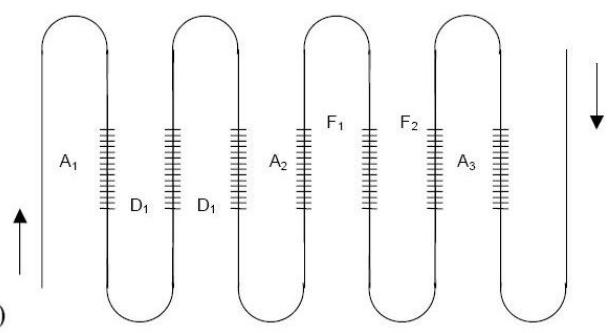

Fig. 2: Storchenbrücke, Winterthur a), picture of one CFRP-cable with sensor fiber meander b), cross section of CFRPcable with positions of sensors c), meander structure of sensor fiber accessible from both sides d).

For each monitored cable a fiber with seven FBG was used as shown in Fig. 2d). The fiber sensors were adhered with epoxy adhesive to the surface. Only the FBG A1, A2 and A3, are used to record strain of the cable. The others are attached to unstrained CFRP wires and serve for compensation and self monitoring as explained below. The FBG D1 and $\mathrm{D} 2$ are attached unstrained to the wires whereas F1 and F2 are adhered in a pre-strained state.

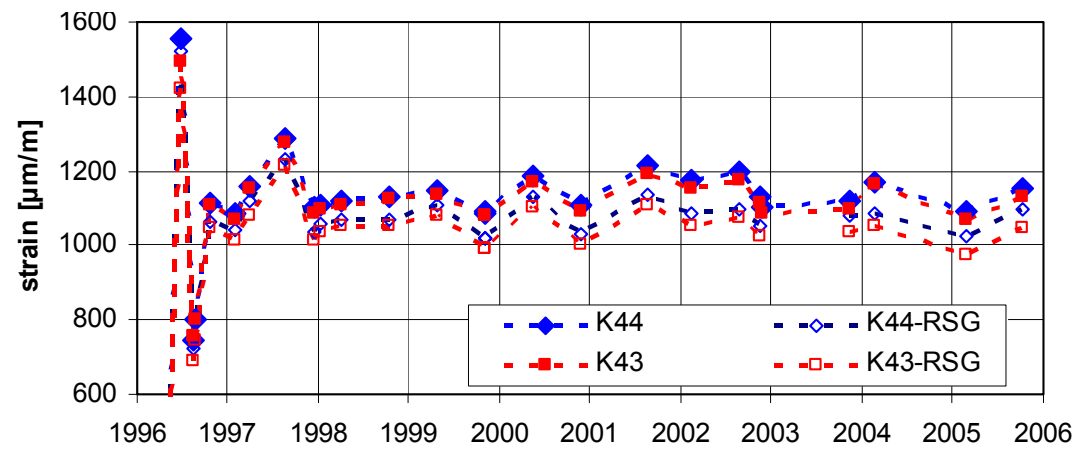

Fig. 3: Comparison of strain measured with FBG and RSG on the Storchenbrücke.

Besides sporadic FBG measurements the cables are monitored continuously with resistive strain gauges (RSG). In Fig. 3 the comparison of FBG (filled markers) and RSG (open markers) measurements for a period of almost ten years are shown. The change of the measurements due to environmental conditions is synchronous. However, the difference between FBG and RSG measurements increases at a rate of about $4 \mu \mathrm{m} / \mathrm{m} /$ year. The RSG measurements have a slightly higher resolution, however, the FBG have in this case better stability over time and the increasing difference can be attributed mainly to the RSG system as will be shown below. 


\section{RELIABILITY OF FIBER OPTICAL SENSOR SYSTEMS (TOP DOWN CONSIDERATIONS)}

Measurement instruments can be easily replaced. Therefore, with respect to hardware reliability, they are of minor importance. However, instrumentation may be of interest when considering the reliability of the measured data itself (chapter 4). The reliability of the components themselves has to be considered (see chapter 5) but care has to be taken to see the reliability function in the context of the complete installed system. Only then, the most critical parts can be figured out and proper redundancies can be built in.

Fig. 4 shows a fault tree diagram for both FBG-systems used in the bridge applications. With help of a fault tree analysis the systematic investigation of the origins of failures and faults is possible. The approach is top-down, starting from an unwanted event and putting together the external or internal influences leading to this event. One advantage is that the interplay of various types of failures and faults can be treated. However, it is not guaranteed, that all are considered. More restrictive but also more costly investigations can be made with FME(C)A (failure modes, effects, (and criticality) analysis) [16]. Creep of adhesive in case of the Storchenbrücke and break of FBG or fiber due to improper embedding in case of the bridge over the Kleine Emme, respectively, were found to be the most probable and thus critical failures. Because the FBG arrangements in both cases were non-repairable and non-replaceable, they were designed with built-in redundancies as will be discussed below.

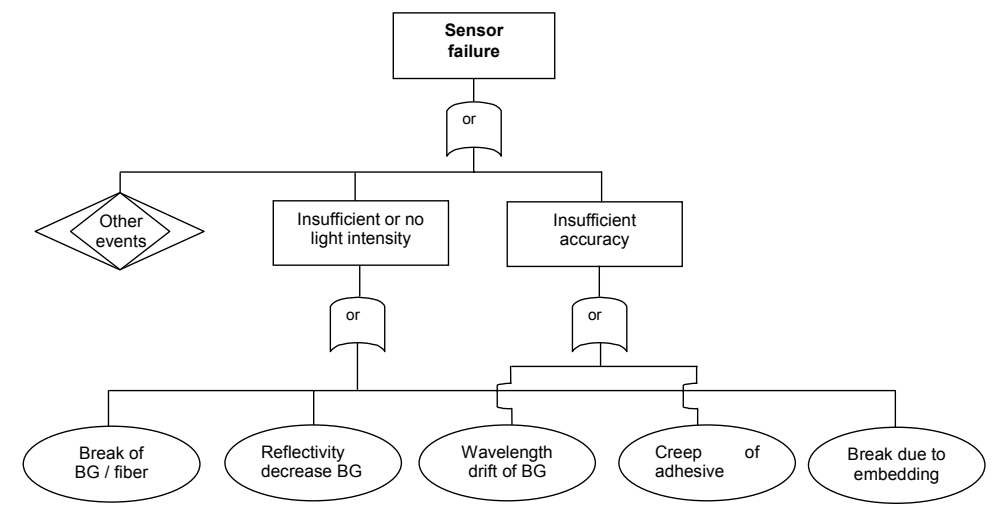

Fig. 4: Fault tree diagram for a FBG sensor system.

We analyzed the FBG systems of both bridges with help of reliability block diagrams RBD [16]. These are event diagrams that help identifying, which elements of a system are necessary for one specific required function. All redundant FBG were hot/active redundancies, i.e., they are subjected to the same load as their counterparts and therefore have the same failure rates. With known failure rates and distributions of the elements in a RBD system reliability can be evaluated either by straightforward calculations or by Monte-Carlo simulations.

Due to lack of data (aging tests or field data) very often neither failure rates nor failure distributions are know or they have large uncertainties. In such cases the calculations are simplified by taking constant failure rates $\lambda$ (i.e., failure free operating times are assumed to be exponentially distributed) and the system has to be modeled qualitatively. Nevertheless, the system parts dominating the overall reliability can be identified by doing sensitivity analysis, i.e., by systematically studying the influence of the input parameters. In addition, by identification of so called minimal cut sets (parts that have to fail simultaneously to produce an outage), the system optimum can be found.

\subsection{Bridge over the Kleine Emme}

No aging models under stress are known, but first field data is available. The sensor system showed early failures, eight FBG failed out of a total number of 21, all of them in the free span (high strain) of the same cable (Fig. 5a)). From this field data a failure rate of approximately $\lambda \approx 7600$ FIT (Failure In Time, 1 FIT $=1$ Failure in $10^{9}$ operating hours) was estimated (taking the cumulated operating hours into account) corresponding to a mean time to failure MTTF of about 132 '000 h. All failures could be attributed to break of FBG and slippage of FBG due to poor embedding (high fiber stress inside the CFRP wire and slippage due to voids and poor interface adhesion, respectively). These failures can be considered as early failures in the first four years. Such failures typically occur at the beginning of the so called bathtube curve (failure rate versus time, with early failure period, constant failure rate, and wear out period, see Fig. 5b). We assume the steady state failure rate to be much lower - at least one or two orders of magnitude. 
In Fig. 6 the RBD is set up for the following required function of the FBG system of the bridge over the Kleine Emme: $\left[\left(\mathrm{S}_{4} \cap C \cap \mathrm{F}_{41} \cap \mathrm{T}_{4}\right) \cup\left(\mathrm{S}_{5} \cap \mathrm{T}_{51}\right)\right] \cap\left[\left(\mathrm{S}_{1} \cap \mathrm{A}_{1} \cap \mathrm{F}_{11}\right) \cup\left(\mathrm{S}_{2} \cap \mathrm{A}_{2} \cap \mathrm{F}_{21}\right) \cup\left(\mathrm{S}_{3} \cap \mathrm{B} \cap \mathrm{F}_{31}\right) \cup\left(\mathrm{S}_{4} \cap C \cap \mathrm{F}_{41}\right)\right]$, i.e. the system is considered to be operating, if at least one of the strain sensors $F_{i j}$, in the free span of the cable and at least one of the three temperature sensors $T_{4}, T_{51}, T_{52}$ is operating. $S_{i}$ represents the fiber splices at the beginning of each of the five wires (Fig. 1). This is considered and designated as minimum requirement since strain information in the anchor head is not required. In the RBD the FBG $\mathrm{F}_{\mathrm{i} 2}$ and $\mathrm{T}_{52}$ do not appear at all, because the failure of one of these does not influence FBG system functionality as defined above. Although the system is still functional if one of the $\mathrm{F}_{\mathrm{i} 2}$ (or $\mathrm{T}_{52}$ ) fails, such a failure can reveal information about the quality of the embedding. Also, these FBG can help identifying drift in sensors or changes in the surveyed structure with help of self-diagnostics procedures.
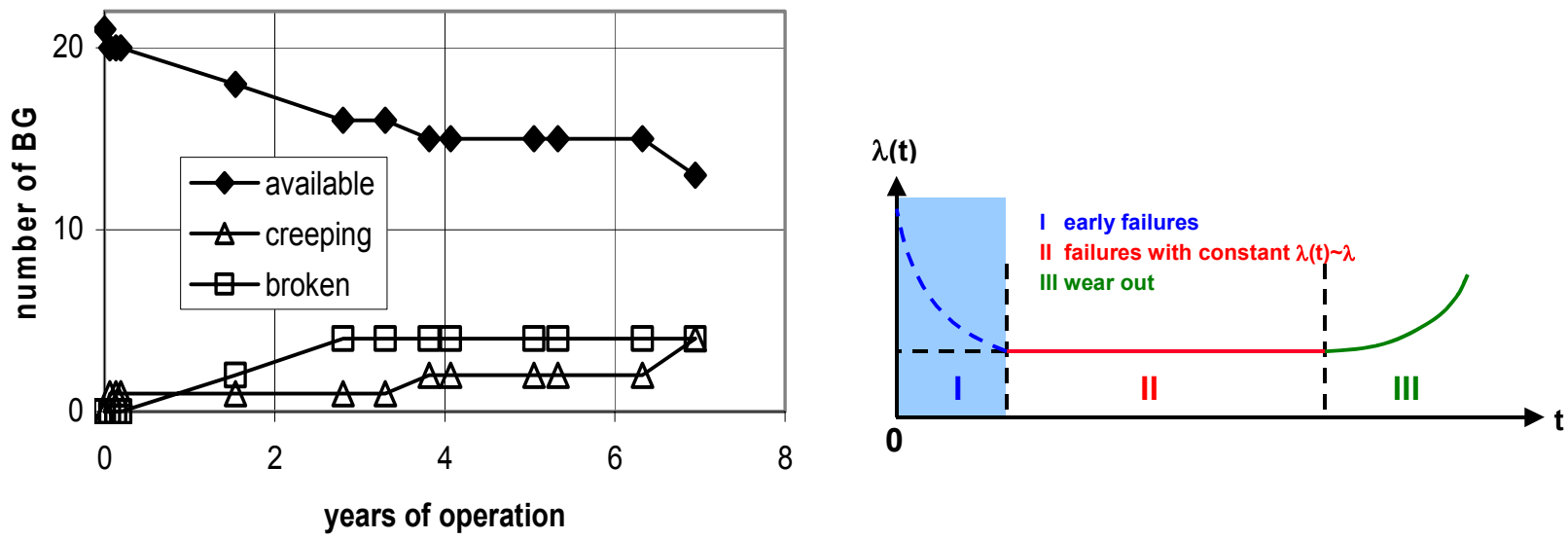

a)

b)

Fig. 5: Failed fiber Bragg gratings with time, all failures observed in the same cable (a), and bath tube curve (b).

A more stringent consideration, designated maximum requirement, also needs strain information in the anchor head by all sensors $\mathrm{A}_{\mathrm{i}}, \mathrm{B}$, and $\mathrm{C}$ yielding a required function: $\left[\left(S_{1} \cap A_{1}\right) \cup\left(S_{2} \cap A_{2}\right)\right] \cap S_{3} \cap B \cap S_{4} \cap C \cap\left[\left(F_{41} \cap T_{4}\right) \cup\left(S_{5} \cap T_{51}\right] \cap\left[\left(S_{1} \cap A_{1} \cap F_{11}\right) \cup\left(S_{2} \cap A_{2} \cap F_{21}\right) \cup F_{31} \cup F_{41}\right]\right.$.

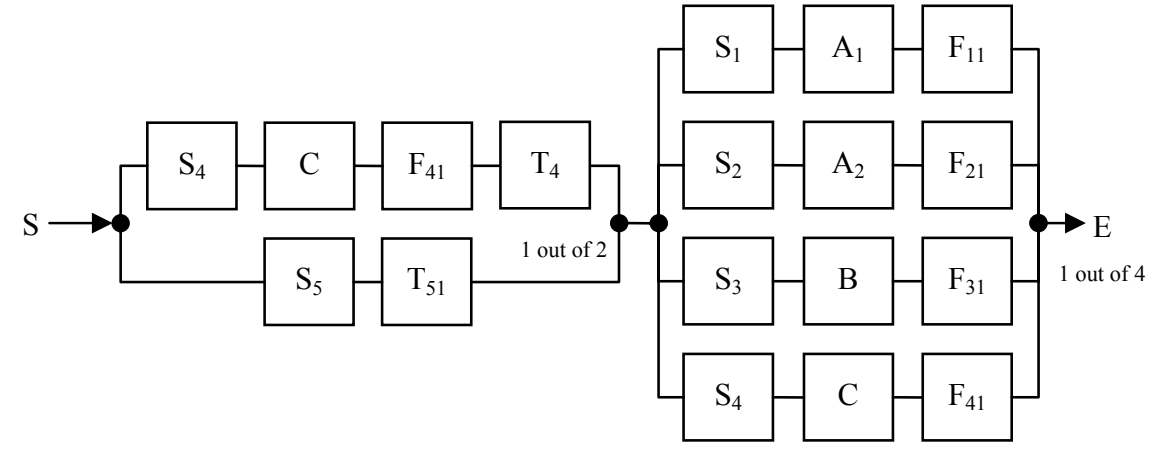

Fig. 6: Reliability block diagram of the FBG system on the bridge over the Kleine Emme, minimum requirement.

Note that $\mathrm{C}, \mathrm{S}_{4}$, and $\mathrm{F}_{41}$ occur two times in the RBD, while the corresponding FBG is physically present only once in the real system. These elements are therefore dependent, i.e. a failure of $\mathrm{C}$ in the physical system is a failure of both elements $\mathrm{C}$ occurring in the RBD. By assigning failure rates or MTBF-values to all elements of the RBD, the system reliability function $\mathrm{R}(\mathrm{t})$ can be plotted and the system mean time to failure $\mathrm{MTTF}_{\mathrm{s}}=\int_{0}^{\infty} R(t) d t$ can be calculated . For illustration purpose, let us consider a numerical example: constant failure rates of the strain sensors $A_{i}, B, C, F_{i j}$, and temperature sensors $T_{i(j)}$, are $\lambda_{s}=7600$ FIT based on the estimate of field data of the bridge over the Kleine Emme and splices $S_{\mathrm{i}}$ have a failure rate of $\lambda_{\text {sp }}=10$ FIT according to [17]. In Fig. 7 reliability R(t), representing the probability that the system is operating at time $t$, is plotted for the case of all elements having failure rates $\lambda_{\mathrm{s}}=7600$ FIT and 
$\lambda_{\mathrm{sp}}=10$ FIT and for cases where elements $\mathrm{B}$ and $\mathrm{C}$ have a failure rate $\lambda_{\mathrm{s}}$ that is 10 times smaller. Calculations were performed with a commercial software tool (Relex) using Monte Carlo simulation.

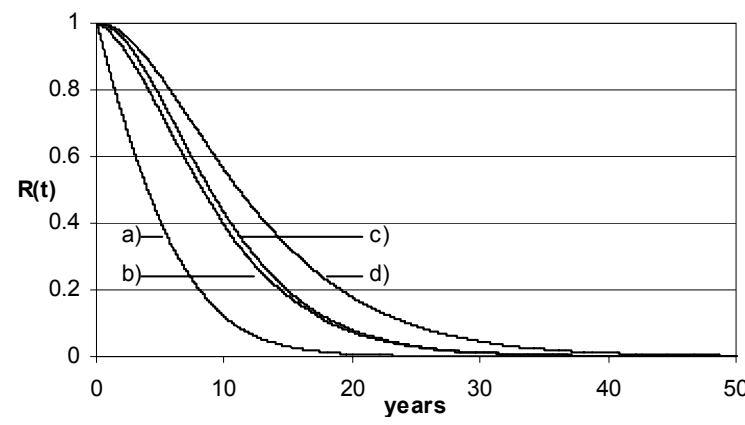

Requirements, failure rates and resulting MTTFs, Kleine Emme

\begin{tabular}{l|l|l|}
\hline Requirement & Failure rates* & $\mathrm{MTTF}_{\mathrm{s}}[\mathrm{h}]$ \\
\hline a) maximum & $\lambda_{\mathrm{s}}, \lambda_{\mathrm{sp}}$ & $4 \cdot 10^{4}$ \\
\hline b) maximum & $\lambda_{\mathrm{s}} / 10$ for $\mathrm{B}, \mathrm{C}, \lambda_{\mathrm{sp}}$ & $8.5 \cdot 10^{4}$ \\
\hline c) minimum & $\lambda_{\mathrm{s}} \lambda_{\mathrm{sp}}$ & $9 \cdot 10^{4}$ \\
\hline d) minimum & $\lambda_{\mathrm{s}} / 10$ for B, C, $\lambda_{\mathrm{sp}}$ & $11 \cdot 10^{4}$ \\
$\begin{array}{l}\text { * } \lambda_{\mathrm{s}} \text { for all elements } \\
\text { is } 10 \text { FIT. } \mathrm{A}, \mathrm{C}, \mathrm{F}, \text { and } \mathrm{T} \text { is } 7600 \mathrm{FIT}, \lambda_{\mathrm{sp}} \text { for splices S }\end{array}$
\end{tabular}

Fig. 7: Reliability $\mathrm{R}(\mathrm{t})$ for the bridge over the Kleine Emme for cases a)-d).

The lower failure rate of a factor of ten for components $\mathrm{B}$ and $\mathrm{C}$ leads to a doubling of $\mathrm{MTTF}_{\mathrm{s}}$ for the maximum requirement and an increase of $\mathrm{MTTF}_{\mathrm{s}}$ by a factor of about 1.3 for the minimum requirement.

\subsection{Storchenbrücke}

In case of the Storchenbrücke the best epoxy adhesive (out of selected samples) was identified by an accelerated aging test [15]. However, any documented field behavior at that time was not known. So far, i.e., since nearly 10 years, none of the FBG failed. Of 14 FBG 10 are strained and did not fail during 9.6 years. The cumulative operating time is $\mathrm{T}_{\mathrm{k}}=14 \cdot 9.6 \cdot 365 \cdot 24 \mathrm{~h}=1^{\prime} 177^{\prime} 300 \mathrm{~h}$. Since the number of failures $\mathrm{n}$ in this time is zero the $\mathrm{MTTF}=\mathrm{T}_{\mathrm{k}} / \mathrm{n}$ is calculated setting $\mathrm{n}$ to 0.5 yielding roughly 2 Mio. hours as MTTF or 500 FIT as failure rate for a sensor. The failure rate of the splices on both ends of a fiber is again taken as $\lambda_{\mathrm{sp}}=10 \mathrm{FIT}$.

The maximum requirement function is defined as: $\left(A_{1} \cup A_{2} \cup A_{3}\right) \cap\left(D_{1} \cup D_{2}\right) \cap\left(F_{1} \cup F_{2}\right)$ for each cable, i.e. at least one strain sensor $\left(\mathrm{A}_{\mathrm{i}}\right)$, one temperature sensor $\left(\mathrm{D}_{\mathrm{i}}\right)$, and one pre-strained (and temperature) sensor for diagnostic purpose $\left(\mathrm{F}_{\mathrm{i}}\right)$ must be functional. The corresponding RBD (Fig. 8) considers the fact that access to the FBG is possible from both sides of the sensor fiber, which is reflected in the series structure of $\mathrm{D}_{2}, \mathrm{~A}_{2}$, and $\mathrm{F}_{1}$ through which the light has to be transmitted in any case. A less stringent requirement - minimum requirement - is $\left(A_{1} \cup A_{2} \cup A_{3}\right) \cap\left(D_{1} \cup D_{2} \cup F_{1} \cup F_{2}\right)$, which leads to simpler RBDs of both, the case with access to both sides and that with access to only one side of the sensor fiber.

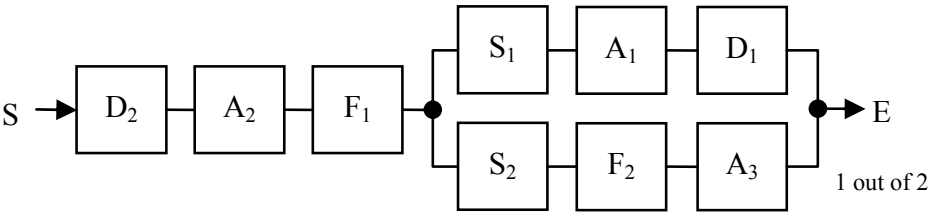

Fig. 8: Reliability block diagram of the FBG system on the Storchenbrücke, maximum requirements, access from both sides of the sensor fiber.

The consequences of the above definitions of required functions and variations in failure rates of components A, D, and $\mathrm{F}$ by a factor of 2 and 10 on system reliability $\mathrm{R}(\mathrm{t})$ and on the resulting $\mathrm{MTTF}_{\mathrm{s}}$ are shown in Fig. 9. The vertical distance of curves b) and d) or curves $f$ ) and g) represents the impact of the light access on both sides of the sensor fiber. The benefit in terms of MTTFs is an increase by factors of 1.3 and 1.5, respectively. The impact of lower failure rates under otherwise identical requirements and access conditions is represented by the vertical distances of curve f) to curves e) and c) with $\lambda_{\mathrm{s}} / 2$ respectively $\lambda_{\mathrm{s}} / 10$ for A2, D2, F1 instead of $\lambda_{\mathrm{s}}$. Here the benefit in terms of MTTFs is an increase by a factor of 1.5 with $\lambda_{\mathrm{s}} / 2$ respectively a factor of 2.5 with $\lambda_{\mathrm{s}} / 10$ for the most critical components A2, D2, and F1.

The two investigated examples of Kleine Emme and Storchenbrücke have shown a large contrast in reliability parameters and therefore the suitability of such non-repairable systems for monitoring or safety purposes is questionable. No failure occurred in 130 cumulated FBG operation years at the Storchenbrücke, while at the bridge over the Kleine Emme 8 of 21 FBG failed in 120 cumulated FBG operation years. This does not indicate an intrinsic problem of the fiber system because the same fiber and FGB were used at both locations. Main differences however exist in the details of implementation and the applied strain on the FBG as shown in table 1. Therefore, in order to achieve useful 
levels of reliability over decades, only well established and controllable methods for the attachment of the fibers / FGB should be used and strain should be kept as low as feasible, see also section 5. As shown for the Storchenbrücke, high reliability over decades can be achieved by a combination of hardware redundancy, redundancy in the measurement process, i.e. light access from both sides of the fiber system, and reliable components with realizable failure rates in the range of 100 FIT.

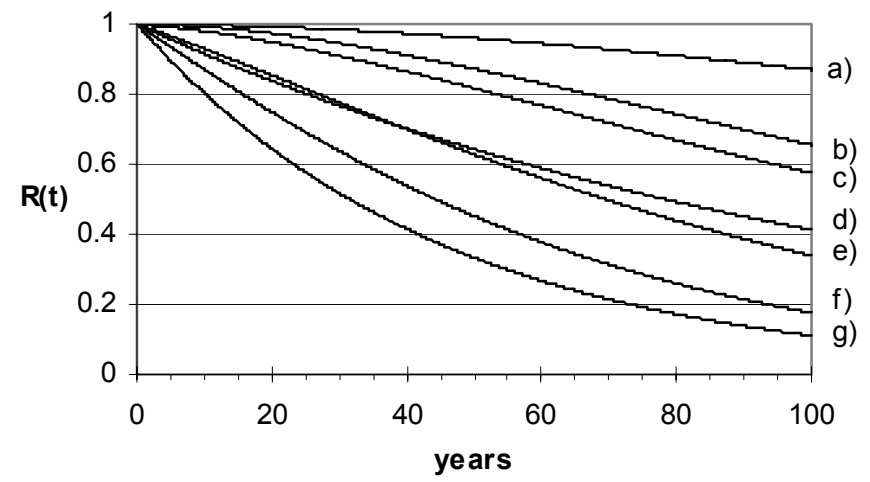

Requirements, failure rates and resulting $\mathrm{MTTF}_{\mathrm{s}}$, Storchenbrücke

\begin{tabular}{|l|l|l|l|}
\hline Requirement & Access & Failure rates* & $\mathrm{MTTF}_{\mathrm{s}}[\mathrm{h}]$ \\
\hline a) minimum & both sides & $\lambda_{\mathrm{s}} / 2$ for all $\mathrm{D}, \mathrm{A}, \mathrm{F}, \lambda_{\mathrm{sp}}$ & $3 \cdot 10^{6}$ \\
\hline b) minimum & both sides & $\lambda_{\mathrm{s}}, \lambda_{\mathrm{sp}}$ & $1.5 \cdot 10^{6}$ \\
\hline c) maximum & both sides & $\lambda_{\mathrm{s}} / 10$ for A2, D2, F1, $\lambda_{\mathrm{sp}}$ & $1.3 \cdot 10^{6}$ \\
\hline d) minimum & one side & $\lambda_{\mathrm{s}}, \lambda_{\mathrm{sp}}$ & $1 \cdot 10^{6}$ \\
\hline e) maximum & both sides & $\lambda_{\mathrm{s}} / 2$ for A2, D2, F1, $\lambda_{\mathrm{sp}}$ & $0.8 \cdot 10^{6}$ \\
\hline f) maximum & both sides & $\lambda_{\mathrm{s}}, \lambda_{\mathrm{sp}}$ & $0.5 \cdot 10^{6}$ \\
\hline g) maximum & one side & $\lambda_{\mathrm{s}}, \lambda_{\mathrm{sp}}$ & $0.4 \cdot 10^{6}$ \\
\hline
\end{tabular}

$* \lambda_{\mathrm{s}}$ for all elements A, D, F is 500 FIT, $\lambda_{\text {sp }}$ for splices S is 10 FIT

Fig. 9: Reliability R(t) for Storchenbrücke and cases a) to h).

Table1: Main implementation differences between Kleine Emme and Storchenbrücke

\begin{tabular}{|l|l|l|}
\hline & Kleine Emme & Storchenbrücke \\
\hline CRFP attachment & embedded & surface attached \\
\hline Attachment process & industrial pultrusion process & Similar to conventional strain gage attachement \\
-process parameters & -"experimental”, pre-damage possible & -controlled, no pre-damage \\
-method experience & -none, first time applied & - high, established method \\
\hline strain $[\mu \mathrm{m} / \mathrm{m}]$ on FBG & $\sim 8000$ & $<3000$ \\
\hline
\end{tabular}

\section{DEPENDABILITY OF FIBER OPTICAL MEASUREMENT SYSTEMS}

\subsection{Measurement set-up: hard- and software}

Measurements systems for any type of fiber optical sensors can be assembled out of off-the-shelve telecom equipment which has typically high reliability. Normally the measurement system is well protected and not exposed to environment and system parts can easily be repaired or replaced. It is therefore not critical in terms of hardware failures compared to the sensors. However, without a well designed measurement system, including hard- and software, long term data consistency is difficult to achieve. Several aspects have to be considered and are discussed below.

As an example, whenever a drift of the data is observed the question has to be answered if the aging of surveyed object, the used sensors, or the instrument causes the drift. Proper sensor applications do not only require the monitoring of the sensor signals per se, but also condition monitoring of the environment, the sensors, and the sensor system. Selfdiagnosis allows to discriminate between a possible permanent degradation of the observed object (with alarm levels depending on severity), a failure of the monitoring system or the fiber sensors, or a reversible short-term loss in signal reliability due to environmental or human influences. Assessing the quality of observation conditions in the working environment is also a key element for reliable sensing. 
Wavelength calibration of the measurement set-up is required. Influences like shaking during transportation or temperature gradients in the instrument during operation influence wavelength measurement accuracy over time. As an example, measurements of fiber Bragg gratings around $\lambda=830 \mathrm{~nm}$ with a grating spectrometer will never be accurate over long term if not a grid of well known wavelengths is provided and is simultaneously measured with each scan together with the Bragg gratings. Scanning the response of the Bragg gratings together with the well-known wavelength peaks of an Argon spectral lamp provides for each measurement a calibration grid leading to an instrument accuracy of $1 \mathrm{pm}$ at any time. Fig. 10 shows a spectrometer scan of 7 Bragg gratings and the 5 Argon spectral peaks serving as calibration grid.

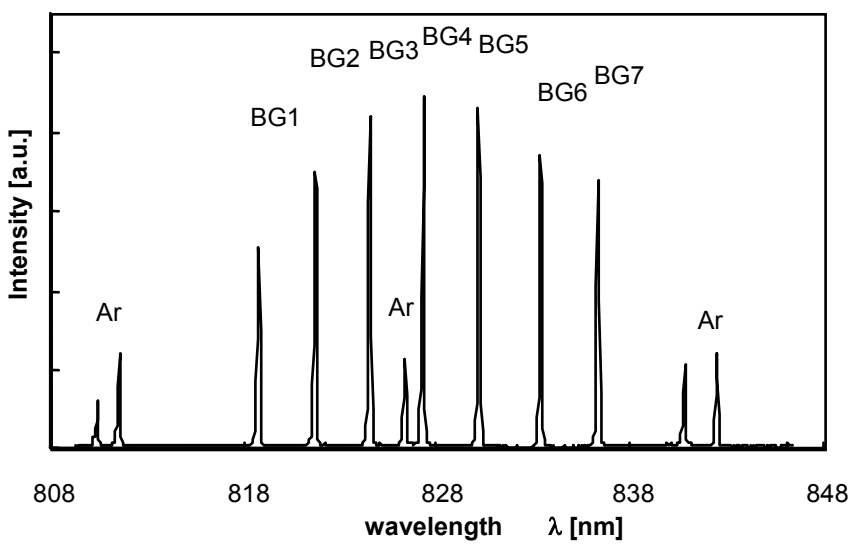

Fig. 10: Calibration spectrum of argon lamp and measured spectrum of a Bragg grating array.

Data should not only be acquired but stored in its original form (e.g. the complete scan of the spectrometer) and not only as a single valued wavelength change or worse as a calculated strain or temperature value. This stored data can then easily be re-evaluated later for controlling, testing or implementation of new evaluation schemes or other purposes. As an example, the implementation of an improve peak fitting algorithm is shown in Fig. 11 (data from the monitoring of the Storchenbrücke). There exist many techniques for peak center evaluation. In reality problems may occur if Bragg grating peaks split due to strain gradients inside the gratings or polarization splitting. This should be avoided by proper attachment and polarization control. The stored wavelengths of all measurements were re-evaluated after a few years. The new algorithm gives the same central wavelength but with improved accuracy, i.e., smaller standard deviation. This can best be seen in the overlapping part of the two different evaluation schemes. The example shows also a typical problem of data inconsistency: the early part of data sets not evaluated with the new algorithm was stored in a different format and for practical reasons the new algorithm was not adapted to the old data set format. In this case, this was not a severe problem; however care should be taken in advance to data storage standards and to have in general a common understanding between customer and provider on the specifications of the system.

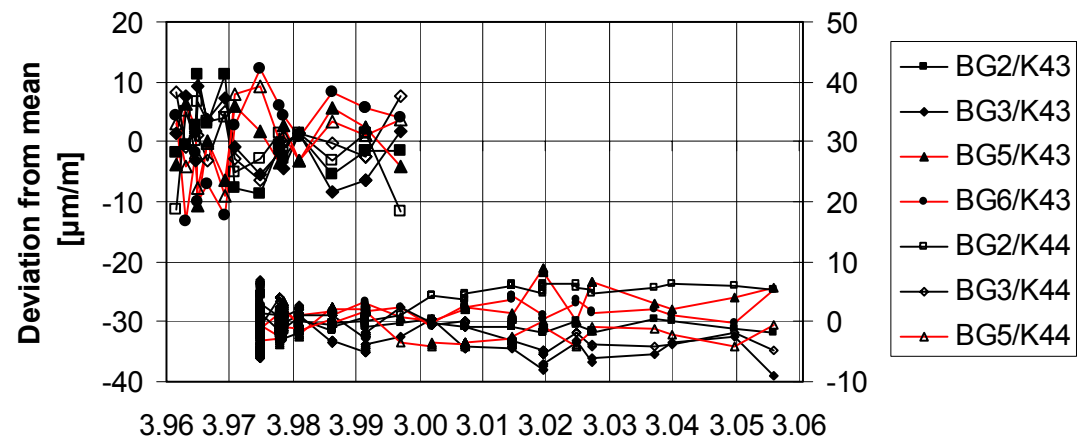

Fig. 11: Comparison of new and old data evaluation algorithm and problem of data consistency.

Also wavelength standards are available for calibration in case of Bragg gratings around $\lambda=1500 \mathrm{~nm}$. Acetylene cells have many absorption peaks in this wavelength region and can be even obtained as NIST traceable standards. In Fig. 12 the absorption lines are given. Also shown are the standard deviations over thousand calibration scans (note scale). The 
scans were performed with a tunable laser with wavelength steps determined by a fiber Michelson interferometer. Also this system scans simultaneously reference wavelength grid and the Bragg gratings [18].

a)

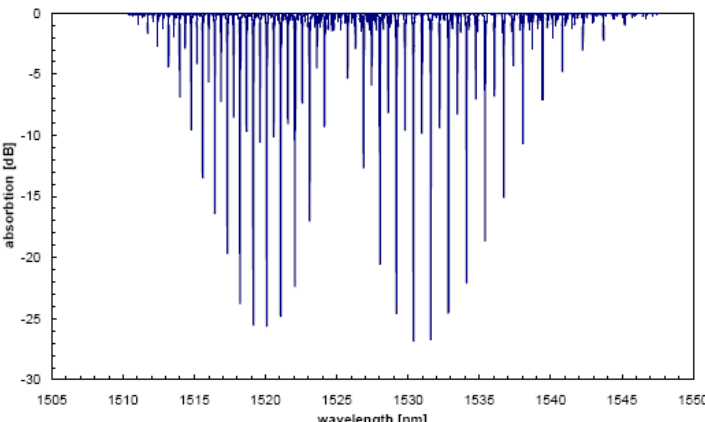

b)

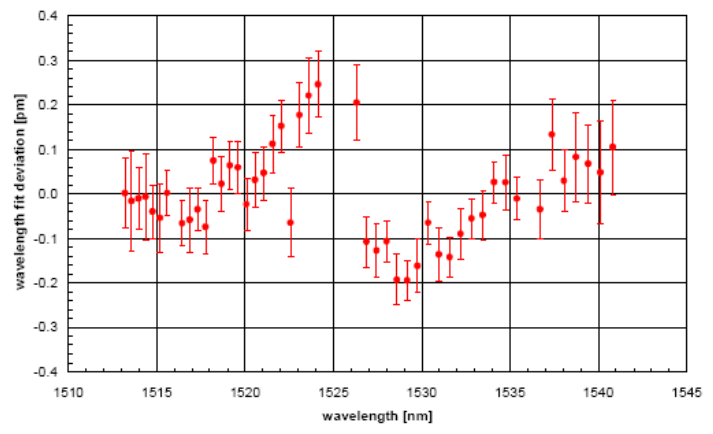

Fig. 12: Acetylene absorption lines (a). Fit deviations and standard deviations (1000 scans) from the calibration of the acetylene absorption peaks (b).

\subsection{Measurement uncertainty}

So far only calibration of the measurement set-up has been discussed. Calibration is also necessary for the response of the Bragg grating sensors. Depending on the required accuracy and the measurement range of interest not only linear terms $\mathrm{A}_{1}, \mathrm{~B}_{1}$ of the wavelength $\Delta \lambda$ change with strain $\sigma$ and temperature $\mathrm{T}$ have to be considered but also quadratic $\mathrm{A}_{2}$, $\mathrm{B}_{2}$ and even mix-terms $\mathrm{B}_{1 \mathrm{~T}}$. Eq. 1 exemplifies this showing the coefficients for a typical fiber Bragg grating at $\lambda=1500 \mathrm{~nm}$.

$\Delta \lambda=\left(B_{1}+B_{1 T} \cdot T\right) \cdot \sigma+B_{2} \cdot \sigma^{2}+A_{1} \cdot T+A_{2} \cdot T^{2} \quad \lambda_{0} \approx 1540 \mathrm{~nm}$

Eq. 1

$B_{1}=16.52 \mathrm{pm} / \mathrm{MPa} \quad B_{2}=-0.5 \cdot 10^{-4} \mathrm{pm} / \mathrm{MPa}^{2} \quad B_{1 T}=1.64 \cdot 10^{-3} \mathrm{pm} / \mathrm{MPa} /{ }^{\circ} \mathrm{C} \quad A_{1}=9.3 \mathrm{pm} /{ }^{\circ} \mathrm{C} \quad A_{2}=9.5 \cdot 10^{-3} \mathrm{pm} /{ }^{\circ} \mathrm{C}^{2}$

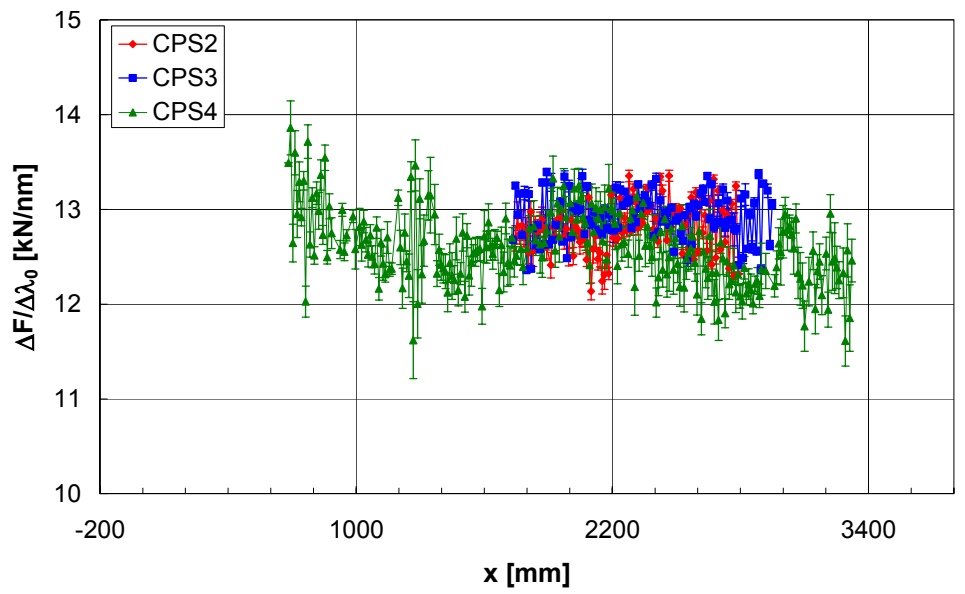

Fig. 13: Determination of the coefficient $B_{1}$ of several hundreds of individual fiber Bragg gratings $(\lambda=830 \mathrm{~nm})$ attached to a steel. The fiber Bragg gratings have distances of $1 \mathrm{~cm}$ and are distributed over three fibers (sensor arrays CPS2-4).

One has to be aware, that these coefficients cannot be assumed to be constant. They are slightly different for each individual Bragg grating in a fiber given manufacturing tolerance. Moreover, they are changed, that is, can be influenced by the fiber coating or by the way the sensors are fixed, clamped, glued, or embedded. A calibration (determination of the coefficients) must therefore be performed under similar conditions the sensors will experience during their mission. It would be best practice if the sensors were already attached to the objects that will finally be monitored, although this in not always possible. Fig. 13 shows a calibration of individual Bragg gratings in three sensor arrays glued to steel bars. This calibration takes into account the influence of coating, glue, and even in homogeneities of the used steel bars which were later built into a concrete specimen. 
However, influence or drift due to the long term exposure to a particular environment (temperature, humidity, salt, others) which add to peak determination uncertainty cannot be estimated in this way. This has to be done by accelerated aging tests.

\subsection{Data consistency}

In addition, any kind of slow drift during the surveillance period due to sensor distortion can be alleviated if it is possible to include a self-calibration technique or at least discrimination schemes which allow distinguishing between sensor failures and/or drift (and failure) of the object to be monitored. For this, sufficient sensors have to be mounted in redundancy to increase first hardware reliability and second information reliability, i.e., data consistency.

Self-diagnostics has to discriminate between a possible permanent degradation of the observed object (with alarm levels depending on severity), a failure of the monitoring system or the fiber sensors, or a reversible short term loss in signal reliability due to environmental or human influences. Assessing the quality of observation conditions in the working environment is a key element for reliable sensing.

Fig. 14 shows the self diagnostic signals of an imaging spectrometer used during a 50 days measurement period of Bragg gratings embedded in glass fiber reinforced rock bolt tested in a tunnel in Switzerland [13]. For every CCD readout of the spectral emission lines of an Argon wavelength calibration lamp the center wavelength (wavelength at center pixel of CCD) and the spectrometer dispersion (in pm/pixel) was determined. Center wavelength change was found to be mainly correlated to the environmental temperature fluctuation. Although such changes are nearly two orders of magnitude larger than the instruments resolution their influence can be properly compensated for long term monitoring. Spectrometer dispersion is a sensitive measure for instrument performance. It should be constant and any increase of its standard deviation or drift reflects degradation of system performance. The observed increase in standard deviation of a factor of 3 was found to be induced by an intensity loss of the Argon spectral lines. In this case the loss was caused by dust settled on the mirrors and grating of the spectrometer and the overall performance could be regained by cleaning the optical elements. Nevertheless, the example shows the importance of self diagnostic signals for long term monitoring.

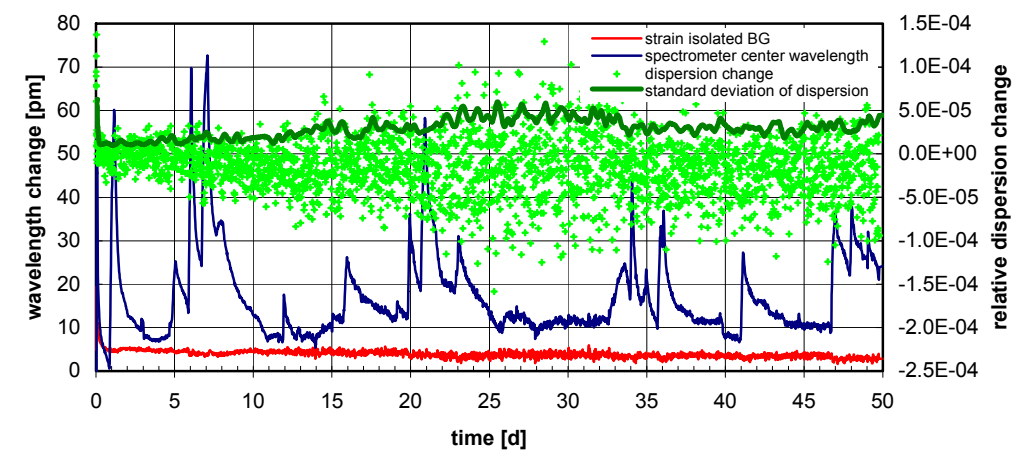

Fig. 14: Self diagnostic signal showing degrading performance of measuring instrument.

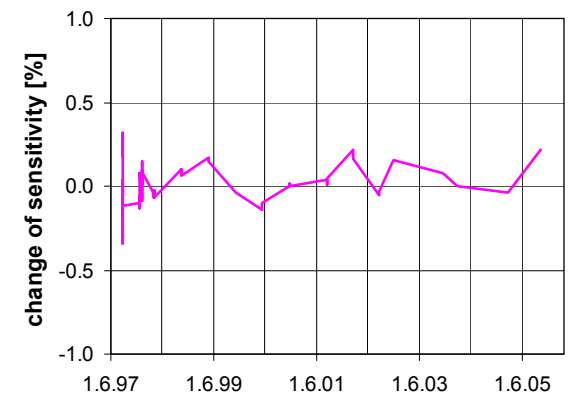

Fig. 15: Relative sensitivity change versus time as self-diagnostic signal for the whole system including instrument failure and sensor drift and degradation.

Another type of self-diagnostics and self-calibration is shown in Fig. 15. Seven of the fourteen Bragg gratings of Storchenbrücke are adhered to unstrained wires within the cables in order to compensate environmental effects. Three of 
them have been pre-strained adhered at strain levels of about twice the level of the active Bragg gratings. The materials, the assembling procedures and the environmental influences are exactly the same for all three types. Any decay in strain transfer would show strain decay in the pre-strained dummy sensors. The relative change of sensitivity is plotted over time and any remarkable change would lead to an inspection of the system. In principle, it is possible to go one step further, e.g. for high risk objects. As the different sensor signals are often redundant to each other - maybe this is even a requirement of optimum sensor deployment strategy - a sophisticated comparison would lead to information which particular sensor is to be about to drift. Only to mention a few, key techniques which may play a future role are those well known from information technology, e.g. neural networks, fuzzy technology, data fusion, fault diagnosis, and condition monitoring.

\section{RELIABILITY OF FIBER OPTICAL COMPONENTS (BOTTOM UP CONSIDERATIONS)}

The top down approach allows estimating the long term performance of planned sensor systems. Its relevance and validation, however, depends on the FIT values of the individual components. To make the most accurate estimation it is necessary to investigate failure mechanisms in a bottom up approach, i.e., for the individual components [19]. If the failure mechanisms are known and understood the temporal behavior can be modeled and lifetime estimation is possible (FIT values can be given). Fig. 16 summarizes causes for fiber degradation and failure. There are mechanisms that attack the fiber, the coating, interfaces like fiber coating interface or the linkage of the fiber to the object or alter the FBG.

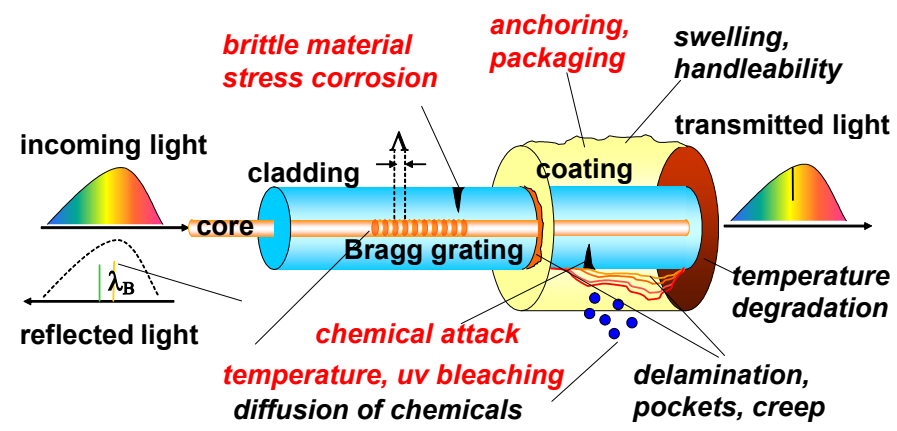

Fig. 16: Failure mechanisms of optical fibers.

\subsection{Fiber sensor coatings, attachments and embedding, and clamping}

The bond of the fiber to the structure is critical for surface application but also for embedded fiber sensors [20]. Several interfaces are responsible for strain transfer between FBG and structure. From the point of view of the FGB the first interface is between core and cladding which is assumed to be unproblematic. The following interface is between cladding and coating. There exists a variety of coatings that are typically polymeric or metallic. In addition, the methods of application and curing vary so it is difficult to assess their aging behavior with respect to mechanical, chemical and physical properties. Two additional interfaces are between cladding and adhesive and between adhesive and structure. Here we have an almost unlimited variety of materials and processes. General rules to make reliability estimations seem impossible to establish and it is necessary to focus on typical systems.

Some types of degradation are shown in Fig. 17. Fig. 17a) is a picture of the single layer acrylate coating rupture in a climate chamber test at $85^{\circ} \mathrm{C} / 85 \%$ rh and at a strain level of $5000 \mu \mathrm{m} / \mathrm{m}$. Under the same condition pockets between fiber and coating are formed, which are probably filled with water (Fig. 17b)). Fig. $17 \mathrm{c}$ ) shows a crack in polyimide coating after 17000 cycles of $\pm 1 \%$ strain at $4 \mathrm{~Hz}$ additional to a static strain of $4 \%$. The cross section of a fiber embedded in a CFRP wire in Fig. 17d) shows an unsatisfactory bond between fiber coating and surrounding material.

To measure the bond strength between fiber and embedding material "push out" method is well suited. This was done for the embedded FBG in the case of the bridge over the Kleine Emme. The push-out tests revealed that the embedding requires improvement. The method is outlined in Fig. 18 a). A slice of a material with embedded fiber is cut perpendicular to the fiber axis. A cylindrical indenter, visualized by the arrow pushes the fiber out of the material. The force is measured as a function of the displacement Fig. $18 \mathrm{~b}$ ). First, the behavior is elastic. Then debonding occurs and finally there is complete failure of the bond. The results shown are for four polyimide coated fibers embedded in CFRP 
wires during the pultrusion process. From these measurements the interfacial debonding energy $\Gamma$ and the product of normal interface stress $\sigma_{\mathrm{n}}$ and friction coefficient $\mu$ can be estimated [20]. Here the average of $\Gamma$ was $190 \mathrm{~J} / \mathrm{m}^{2}$ and the product $\left(\sigma_{\mathrm{n}} \cdot \mu\right)$ was $18 \mathrm{~N} / \mathrm{mm}^{2}$.

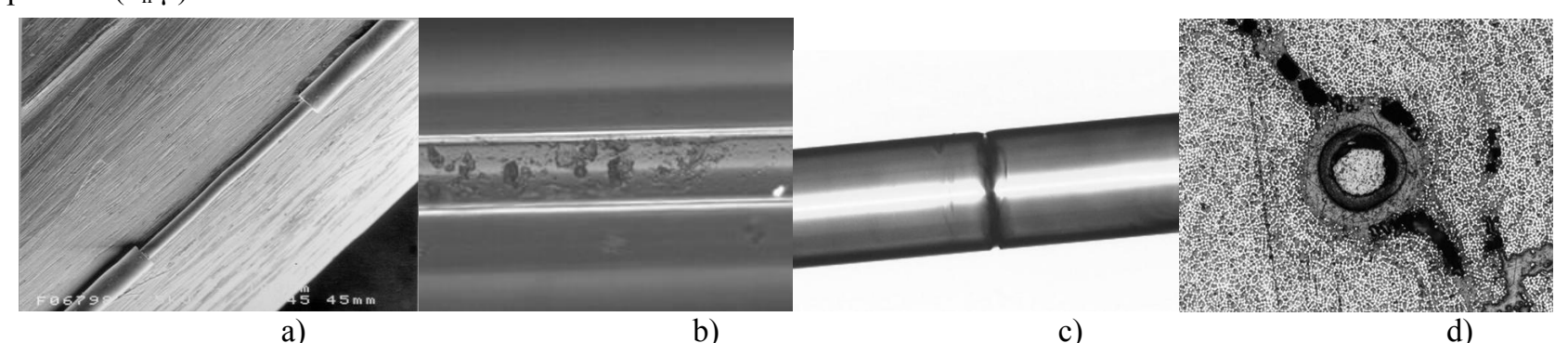

Fig. 17: Pictures of various fiber coating degradations.

a)

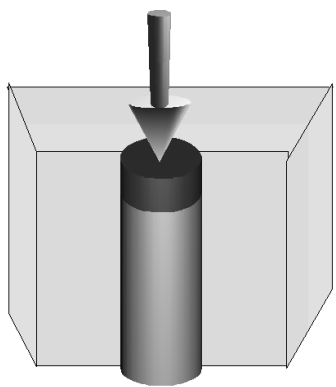

b)

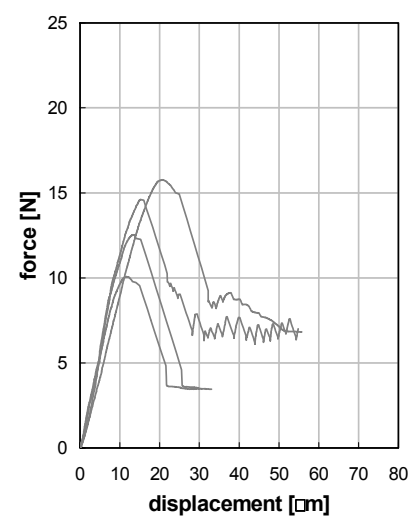

Fig. 18: Principle of push out test a), results for polyimide fiber embedded in CFRP b).

Another approach to reduce the number of interfaces between fiber and object is shown in Fig. 19. It was intended to be used in a high pressure down hole application [21]. The bare fiber is directly clamped in a copper ring by the device outlined in Fig. 19a). By pressing the conical end of the upper part into the copper, it is deformed resulting in a tight connection. However the polarization phase increased with the clamping pressure as shown in Fig. 19c).

a)

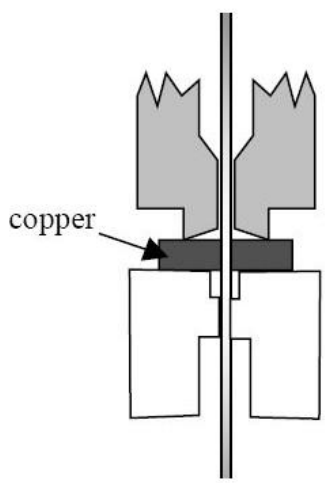

b)

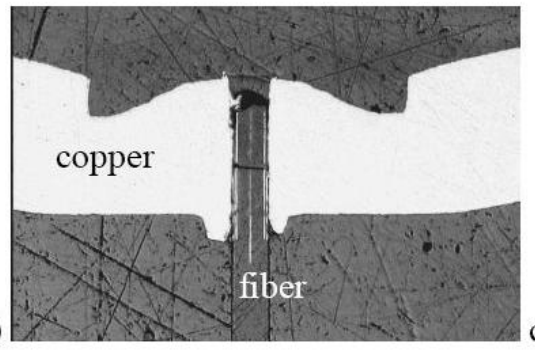

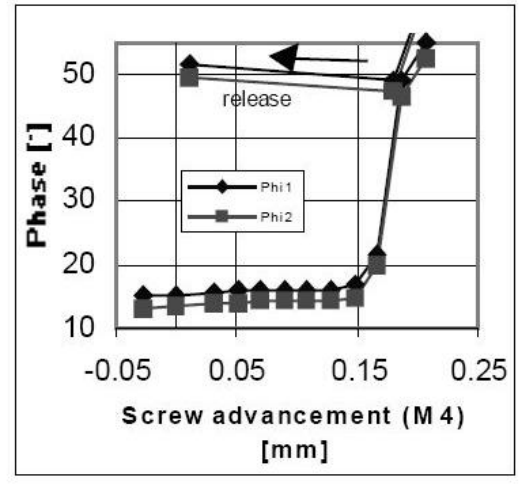

Fig. 19: Scheme of copper-pressing ring (a), picture of polished cross section (b), optical polarization phase change due to clamping of the copper ring (c).

\subsection{Optical fiber Bragg gratings mechanical and thermal reliability}

Glass is a brittle material and susceptible to stress corrosion resulting in degradation and failure under applied stress. Compared to telecom, fibers for sensing application are often under permanent stress. The degradation is accelerated at 
elevated temperature and in the presence of chemical agents. The reduction of mechanical strength of fibers under load can be modeled with a power law [22-25]:

$$
S(t)^{n-2}=S_{I}^{n-2}-\frac{1}{B} \int_{0}^{t} \sigma^{n}(\tau) d \tau
$$

$\mathrm{S}(\mathrm{t})$ is the strength at time $\mathrm{t}, \mathrm{S}_{\mathrm{I}}$ the initial fiber strength, B the strength preservation factor, $\sigma$ the applied stress and $\mathrm{n}$ the corrosion susceptibility factor. To estimate $\mathrm{S}(\mathrm{t})$ under given stress conditions the constants $\mathrm{S}_{\mathrm{I}}$, $\mathrm{B}$ and $\mathrm{n}$ have to be known. They can be derived e.g. from dynamic tensile load tests. In Fig. 20 a) typical results of dynamic tensile tests are given as a Weibull distribution of the reduced intercept $\mathrm{X}\left(=\mathrm{B}^{1 /(\mathrm{n}-2)} \cdot \mathrm{S}_{\mathrm{I}}\right)$ for three different environmental conditions (air $21{ }^{\circ} \mathrm{C}, 50 \% \mathrm{rh}$; argon gas at $23{ }^{\circ} \mathrm{C}$ and $230^{\circ} \mathrm{C}$, low humidity). Each trace consists of data taken at the three strain rates $0.5,10$, and $200 \% / \mathrm{min}$. This allows to determine the required constants for these three cases and to make lifetime prediction as shown in Fig. $20 \mathrm{~b}$ ). The expected time to failure $t_{\mathrm{f}}$ is even in the case of argon at $230{ }^{\circ} \mathrm{C}$ more than a factor $10^{5}$ higher than in air at $50 \% \mathrm{rh}$ around a stress of $2 \mathrm{GPa}$, illustrating the strong influence of the relative humidity.
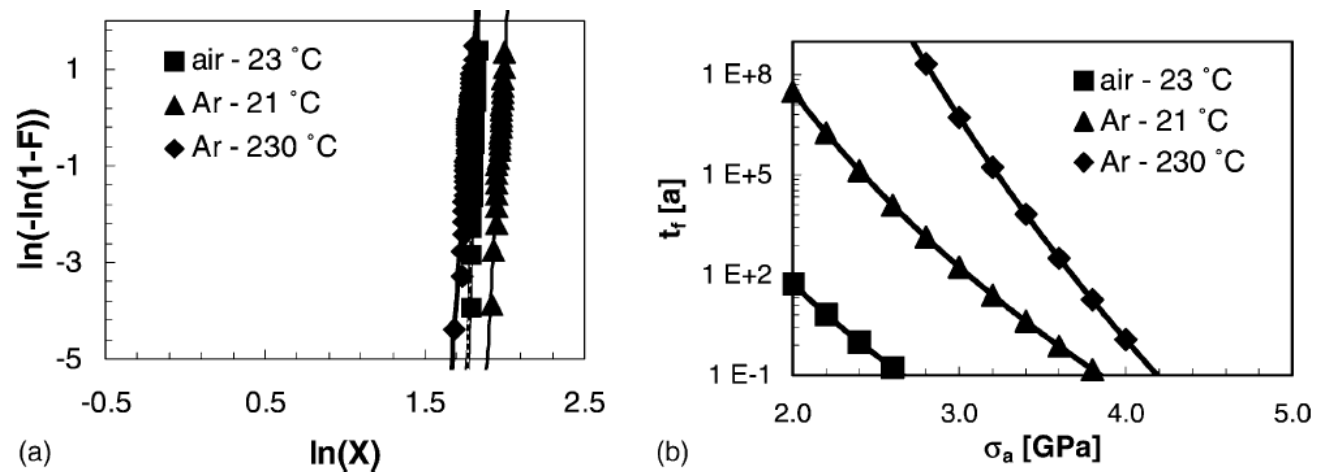

Fig. 20: Weibull distribution of tensile load test under three different environmental conditions a) and predicted time to failure b).
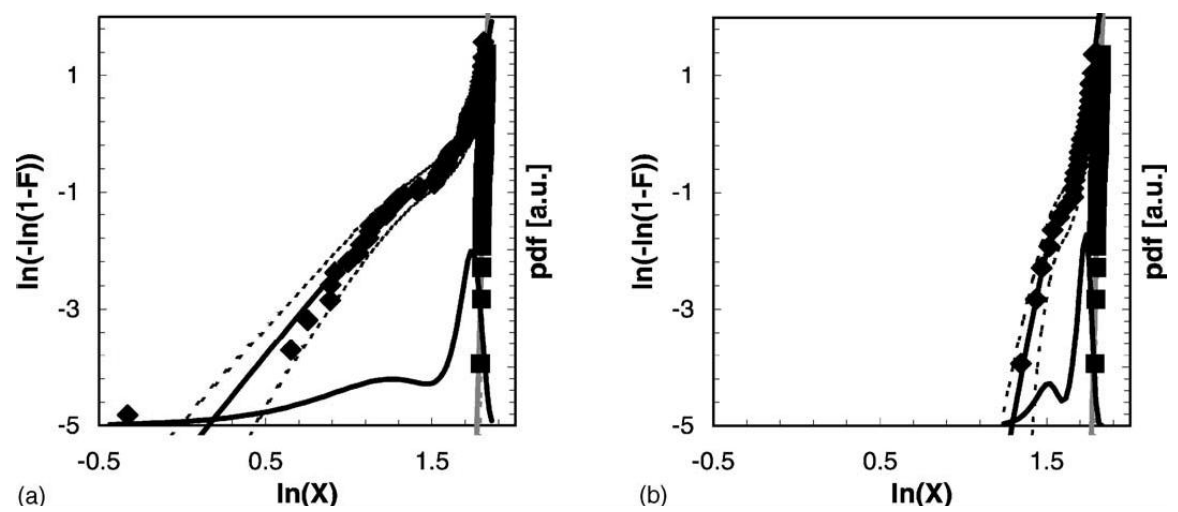

Fig. 21: Comparison mechanical strength of "stripped-recoated" FBG before and after proof-test (a, b). The straight lines are the pdf of the corresponding pristine fiber.

The results given above are valid for pristine fibers. The results alter considerable for FBG produced with a stripping and re-coating process (diamonds in Fig. 21 a). The result for the pristine fiber is also given (squares). There is a multitude of FBG with extremely low breaking strength. Estimating the probability density function (pdf) reveals a bimodal behavior, i.e. the production process introduced a defect with a new failure mode, and the FBG can be seen as a mixture of two sets with different properties, one with the new defect and one without. The time to fail is extremely reduced. However a proof test can eliminate the low strength samples. The disadvantage of the proof test is that the strength of FBG which are close to proof test level is reduced by the test itself. However, this is acceptable as Weibull diagram of the proof-tested FBG shows (Fig. 21b): The low strength FBG are eliminated.

Another source of sensor drift or failure is the decay of the FBG. UV inscribed FBG consist of periodically excited meta-stable states in the core of the fiber, which leads to an increase of the average index of refraction. The excited 
states decay under thermal excitation. This results not only in a reduction of the reflectivity but also in a decrease of the average refractive index within the FBG and hence to a wavelength shift. Fig. 22 shows the annealing behavior of a high reflectivity FBG. With this data the thermal decay master curve $[26,27]$ can be derived. It is a relation between decay of the refractive index and the demarcation energy $E_{d}=k_{b} \cdot T \cdot \ln \left(v_{0} \cdot t\right)$. $v_{0}$ depends on the type of FBG and is for the given example $2 \cdot 10^{9} / \mathrm{s}$. If a maximum thermal drift at a certain working temperature is required, the master curve allows calculating the corresponding annealing condition.

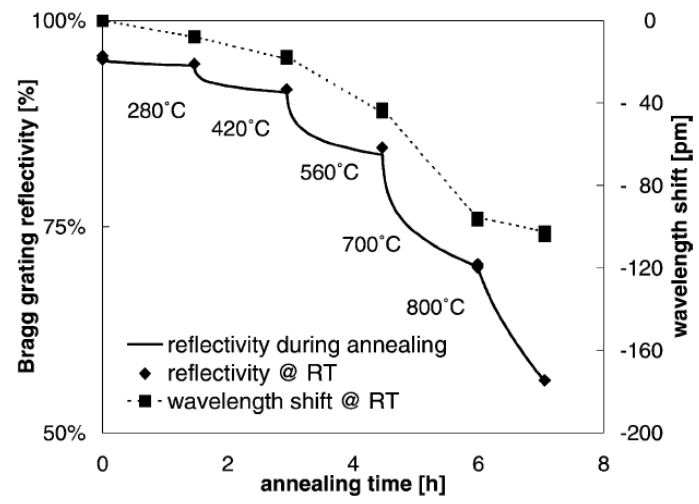

Fig. 22: Reflectivity decay and wavelength shift due to annealing.

\section{MAINTAINABILITY OF FIBER OPTICAL SENSOR SYSTEMS}

Maintainability of sensing systems facilitates the realization of reliable long term monitoring [28]. If all parts of a system can be repaired or replaced, the requirements on reliability are less strict. However, even if the sensing element can be replaced it has to be guaranteed that the data is consistent, i.e., that the new measurements reference to the same origin. This is difficult if a sensor measures only changes and has no absolute relation to the quantity to be measured as it typically the case with FBG where only shifts in wavelength are measured. Either the monitored structure can be temporarily released to a reference state or there must be provision or procedures for alternative determination of the actual value of the measured quantity. However, repair is often impossible at reasonable cost if parts of the sensing system are inaccessible or embedded in the structure as in the case of the two bridges. In such cases high reliability of the components, well established procedures and redundancy are essential.

\section{CONCLUSIONS}

Long term monitoring with a time horizon of decades is difficult if a system contains any parts that are not maintainable. Unfortunately, this is often the case in civil engineering structures, where sensors and components are applied at locations which are inaccessible with reasonable effort after construction. Even if replacement is possible continuity of the data is questionable as long as there are no other methods to assess the quantity to be measured and the correlation of the surveyed system and the sensors maybe lost. Redundancy can improve RAM of a system but complexity increases. If however, a non-redundant system has a low reliability of e.g. $50 \%$ over the lifetime of the structure, expensive redundancy and probably unreasonable installation costs would be necessary to achieve useful reliability. Additionally, more complexity often introduces new or unexpected failure modes.

Another nuisance is that a sensor degrades but is still responding as it can happen with creep or bleaching of a FBG. Therefore, it is a big improvement if the reliability of the monitoring system can be verified during operation, and that failure of the monitoring system can be distinguished from changes in the structure, as in the case of the Storchenbrücke.

It is necessary that provider and customer of fiber optical equipment have a common understanding on the specification of a system. Standards help, but care has to be taken, that such standards are not only intelligible but also sufficiently accurate. Classification of environmental conditions are defined in the standards in the "IEC 70721" group. Guidelines and recommendations should be established which types of fiber optical monitoring elements, systems, and procedures are suitable for typical environmental conditions based on results of reliability investigations and what are the required investigation to qualify new elements. Some recommendations that are used in telecom can be used but many problems particular to fiber optical sensing have to be addressed individually and guidelines still have to be established. 


\section{ACKNOWLEDGEMENT}

The material presented herein is the result of work done at Empa over several years with many academic and industrial collaborators. Special thanks we owe to Francis Berghmans, Brian Culshaw, and Wolfgang Habel for their valuable input to this paper.

\section{REFERENCES}

1. K. O. Hill, G. Meltz, Fiber Bragg Grating Technology Fundamentals and Overview, J. Lightwave Technology, 15(8), 1265-76, 1997

2. $\quad$ Y.-J. Rao, In-Fibre Bragg Grating Sensors, Meas. Sci. Technol., 8, 355-75, 1997

3. A. Méndez, T. F. Morse, Overview of optical fiber sensors embedded in concrete, SPIE 1798, 205-16, 1989

4. C. I. Merzbacher, A. D. Kersey, E. J. Friebele, Fiber optic sensors in concrete: a review, Smart Mater. Struct. 5, 196-208, 1996

5. R. Maashant, T. Alavie, R. M. Measures, M. Ohn, S. Karr, D. Glennie, C. Wade, G. Tadros, S. Rizkalla, Fiber optic Bragg grating sensor network installed in a concrete road bridge, SPIE 2191, 457-65, 1994

6. P. L. Fuhr, D. R. Huston, T. P. Ambrose, Interrogation of multiple embedded fiber sensors in civil structures using radio telemetry, Smart. Mater. Struct., 2, 264-9, 1993

7. W. R. Habel, D. Hofmann, Determination of structural parameters concerning load capacity based on fibre-Pabry-Perotinterferometer, SPIE 2361, 176-9, 1994

8. D. Inaudi, A. Elamari, S. Vurpillot, Low coherence interferometry for the monitoring of civil engineering structures, SPIE 2361, 216-9, 1994

9. R.-C. Tennyson, A.-A. Mufti, S. Rizkalla, G. Tadros, B. Benmokrane, Structural health monitoring of innovative bridges in Canada with fiber optic sensors, Smart Mater. Struct., 10(3), 560-73, 2001

10. P M. Nellen, R. Brönnimann, U. Sennhauser, C. G. Askins, M. A. Putnam, Strain measurements on concrete beam and carbon fiber cable with distributed optical fiber Bragg grating sensors, Opt. Eng. Vol 35(9), 2570-7, 1996

11. B. Culshaw, W. Habel, Fibre Sensing: Specifying components and systems, NIST special publication 1024, Technical Digest: Symposium on optical fiber mesurements, 179-90, 2004

12. R. Brönnimann, P. M. Nellen, P. Anderegg, U. Sennhauser, Application of optical fiber sensors on the power dam of Luzzone, SPIE 3407, 386-91, 1998

13. A. Frank, P. M. Nellen, R. Brönnimann, U. Sennhauser, Fiber optical Bragg grating sensors embedded in GFRP rock bolts, SPIE 3670, 497-504, 1999

14. R. Brönnimann, P. M. Nellen, U. Sennhauser, Reliability monitoring of CFRP structural elements in bridges with fiber optical Bragg grating sensors, J. Intelligent Material Systems and Structures, 10(4), 322-9, 1999

15. U. Sennhauser, R. Brönnimann, P. M. Nellen, Reliability modeling and testing of optical fiber Bragg sensors for strain measurements, SPIE 2839, 64-75, 1996

16. IEC 60812 Analysis techniques for system reliability - Procedure for failure mode and effects analysis (FMEA)

17. IEC TR 62380 Reliability data handbook - Universal model for reliability prediction of electronics components, PCBs and equipment

18. A. Frank, P. M. Nellen, U. Sennhauser, Fiber adhesive joint analysis with intra-Bragg-grating sensing, SPIE 4185, 784-7, 2000

19. F. Berghmans, Reliability of components for fiber optic sensors, SPIE 5758, 417-26, 2005

20. P. M. Nellen, A. Frank, P. Mauron, U. Sennhauser, Tight buffered optical fiber sensor cables, Communication cables and related technologies, A. L. Harmer (ed.), Proc. Euro Cable Conference'99, 334-7, 1999

21. P. M. Nellen, P. Mauron, A. Frank, U. Sennhauser, K. Bohnert, P. Pequignot, P. Bodor, H. Brändle, Reliability of fiber Bragg grating based sensors for downhole applications, Sensors and Actuators A 103, 364-76, 2003

22. F. P. Kapron, H. H. Yuce, Theory and measurement for predicting stressed fiber lifetime, Opt. Eng. 30(6):700-8, 1991

W. Griffioen, T. Breuls, G. Cocito, S. Dodd, G. Ferri, P. Hasløv, L. Oksanene, D. Stockton, T. Svensson, COST 218 evaluation of optical fibre lifetime models, SPIE 1791, 190-201, 1992

24. M. J. Matthewson, Optical fiber reliability models, in Fiber optics reliability and testing, SPIE Conf. Proc., D. K. Paul, Ed., 1994

25. International Standard IEC 60793-1-3, Part I, section 3, Optical Fibres: Measuring Methods for Mechanical Characteristics, 1995

26. T. Erdogan, V. Mizrahi, P. J. Lemaire, D. Monroe, Decay of ultraviolet-induced fiber Bragg gratings, J. Appl. Phys. 76(1), 73-80, 1994

27. S. Kannan, J. Z. Y. Guo, P. J. Lemaire, Thermal stability analysis of UV-induced fiber Bragg gratings, J. Lightwave Techn. 15(8), 1478-83, 1997

28. R. Tennyson, Installation, Use, and Repair of Fibre Optic Sensors, ISIS Canada, ISBN 0-9689006-3-1, 2001 